\title{
Social interaction influences the evolution of cognitive biases for language
}

$\begin{array}{lll}\text { Bill Thompson } & \text { Seán G. Roberts } & \text { Kenny Smith } \\ \text { bill@ling.ed.ac.uk } & \text { sean.roberts@mpi.nl } & \text { kenny@ling.ed.ac.uk } \\ \text { Language Evolution and } & \text { Language and Cognition Department, } & \text { Language Evolution and } \\ \text { Computation Research Unit, } & \text { Max Planck Institute for Psycholinguistics } & \begin{array}{l}\text { Computation Research Unit, } \\ \text { University of Edinburgh }\end{array} \\ \text { www.ReplicatedTypo.com } & \text { University of Edinburgh }\end{array}$
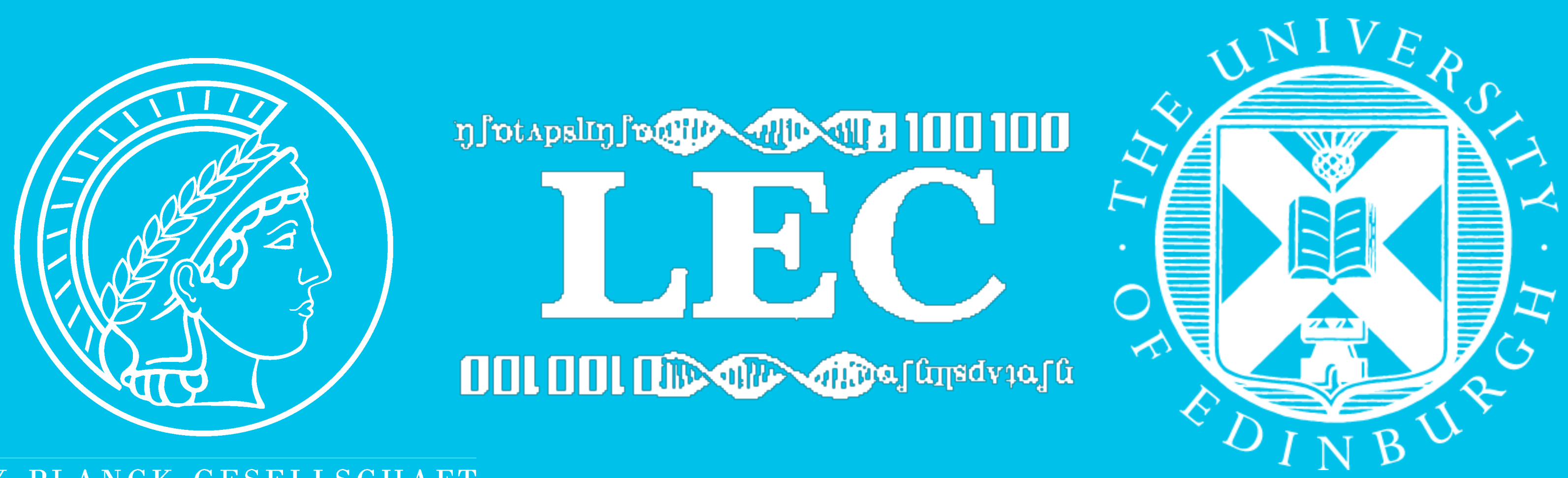

\section{Introduction}

We extend a computational Bayesian model of iterated learning with generations of agents learning multiple languages (Burkett \& Griffiths, 2010). We show that the amount of linguistic diversity that emerges is affected by both the prior expectations of the learners and the social dynamics of the society in which they live. $\underset{\text { biases }}{\text { Prior }}+\underset{\text { evolution }}{\text { Cultural }}+\underset{\text { evolution }}{\text { Biological }}+\underset{\text { fitness }}{\text { Communicative }}=\begin{gathered}\text { Linguistic } \\ \text { diversity }\end{gathered}$

\section{A model of bilingual cultural transmission}

There are two possible languages. Learners can use them in different proportions. Learners observe a set of utterances $d$. Utterances can take one of two forms $\left(u_{1}\right.$ or $\left.u_{2}\right)$ which are diagnostic of one of two languages $l_{0} \& l_{1}$, given some noise $\varepsilon=0.05$ :

$P\left(u_{i} \mid l_{i}\right)=1-\varepsilon \quad$ and $\left.P\left(u_{i} \mid l_{j \neq i}\right)=\varepsilon\right)$

Each learner infers by Bayesian induction the frequencies of two possible languages, and induces a hypothesis, $h_{0}=1-h_{1}=P\left(l_{0}\right) \sim P\left(d / h_{0}\right) P\left(h_{0}\right)$

The likelihood is the product of probabilities for each function: $P(d \mid h)=\prod_{d} P\left(d_{i} \mid l_{0}\right) h+P\left(d_{i} \mid l_{1}\right) 1-h$

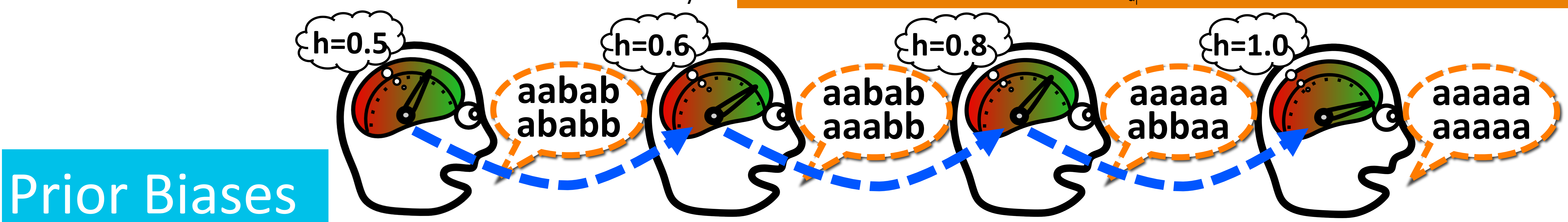

Learners have two prior biases: One favouring the use of each language in a particular proportio
During inference, hypotheses $h$ are drawn from a Dirichlet process prior with base distribution $G_{0}$ and concentration parameter $\alpha$. G $G_{0}$ specifies a distribution over the two possible language types. $\alpha$ regulates the influence of $G_{0}$ during inductive inference: as $\alpha \rightarrow \infty$, learners will induce hypotheses strongly determined by their prior preferences, so that $h \approx G_{0}$; as $\alpha \rightarrow 0, h$ is determined largely by the learner's experiences. In the simulations below, $G_{0}=(0.6,0.4)$.

\section{Cultural evolution}

Learners pass on their language culturally.

After a learner chooses a hypothesis, it produces utterances according to that hypothesis. These utterances become part of the input for the next generation of learners. We can track how the distribution of languages and priors changes over time. Previous work has shown

that cultural evolution can amplify prior biases (see Smith \& Thompson, 2012).

\section{In our context we can interpret $\alpha$ as determining a learner's expectations about linguistic} diversity. High a leads learners to expect a wide distribution of languages in the population. Low $\alpha$ leads learners to expect homogeneity: linguistic variation is discounted in favour of monolingual hypotheses.

C The probability of reproducing is based on social interaction. We test several metrics, including rewarding communicative

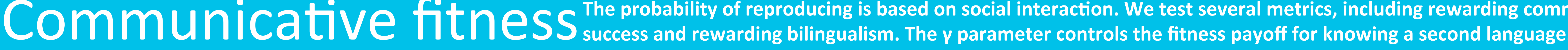

$$
\begin{aligned}
& \text { Mon } \\
& \text { This } m \\
& \text { conve } \\
& \text { partic } \\
& \text { (monc } \\
& \rho_{m}(\text { h } \\
& \text { This } \\
& \text { (Sm }
\end{aligned}
$$

